\title{
Tiyofen ve Furan Halkaları İçeren Makrosiklik Bileşiklerin Sentezleri ve Antimikrobiyal Özelliklerinin İncelenmesi
}

\author{
Hafize ÖZCAN \\ Trakya Üniversitesi, Fen Fakültesi, Kimya Bölümü, 22030, Edirne \\ (ORCID: https://orcid.org/0000-0002-8031-6755)
}

(Alınış / Received: 15.10.2018, Kabul / Accepted: 04.03.2019, Online Yayınlanma / Published Online: 24.04.2019)

\section{Anahtar Kelimeler}

Taç eter,

Makrosiklik,

Antimikrobiyal,

Furan,

Tiyofen
Özet: Makrosiklik bileşikler, kimyanın pek çok alanında farklı uygulamalara sahip işlevsel bileşiklerdir. Bu çalışmada da furan ve tiyofen heterosiklik halkalarını içeren yeni makrosiklik eterler farklı reaksiyon şartları denenerek, en verimli şekilde sentezlenmiștir. Ayrıca sentezlenen bu bileşiklerin Escherichia coli ATCC 25922, Salmonella thphimurium ATCC 14028, Staphylococcus aureus ATCC 25923, Bacillus cereus ATCC 11778 ve Listeria monocytogenes ATCC 19115 bakterilerine karşı antimikrobiyal aktiviteleri, Candida albicans ATCC 10231 mayaları üzerinde antifungal aktiviteleri incelenmiştir. Sentezlenen bileşiklerin bazı bakteri türlerine karşı llımlı etki gösterdiği bulunmuştur.

\section{Synthesis and Analysis of Antimicrobial Properties of Macrocyclic Compounds Containing Thiophene and Furan Rings}

\section{Keywords}

Crown ether,

Macrocyclic,

Antimicrobial,

Furan,

Thiophene

\begin{abstract}
Macrocylic compounds are functional compounds which have different applications in many fields of chemistry. In this work, new macrocyclic ethers containing furan and thiophene rings were obtained in good yields using different methods. In addition, antimicrobial activities of these compounds against Escherichia coli ATCC 25922, Salmonella thphimurium ATCC 14028, Staphylococcus aureus ATCC 25923, Bacillus cereus ATCC 11778, and Listeria monocytogenes ATCC 19115 bacteria and antifungal activity on Candida albicans ATCC 10231 were investigated. It has been found that the synthesized compounds show a moderate effect against some bacterial species.
\end{abstract}

\section{Giriş}

Kimyanın birçok alanında, doğal ve sentetik hetero halkalı bileșikler için geniş bir uygulama alanı vardır. Hetero halka içeren makrosiklik bileşikler de özellikle katyon, anyon veya nötral molekülleri içlerine hapsedebilecek veya bağlayabilecek bir boşluğa sahip olduklarından dolayı oldukça önemli bir bileşik sınıfıdır. Bu bileşiklerin ilaç kimyasında antimikrobiyal, antitümör reaktif, anorganik kimyada ligand, boya ve fotoğraf malzemesi olmaları yanında pek çok biyokimyasal reaksiyonda katalizör olarak da rol aldıkları bilinmektedir [1-3]. Ayrıca B12 vitamininin sentezi, fotosentez gibi temel birçok biyolojik işlev için kullanılan doğal bazı makrosiklik bileşikler ve bu bileşiklerden oluşan farklı metal kompleksleri bilinen en güncel örneklerdendir [4-6]. $\mathrm{Bu}$ özelliklerinin dışında hücrelerde $\mathrm{Na}^{+} / \mathrm{K}^{+}$ seçiciliğini düzenleyebildikleri, sentetik iyonofor, terapeutik oldukları, antibiyotik olarak kullanılabildikleri, farklı biyolojik aktivitelere sahip oldukları ve membranlardan metal katyonlarının taşınmasında kullanıldıkları bulunmuştur [7-8]. Piridin içeren makro halkaların ise floresan redoks açma-kapama, redoks katalizörü, ve antibakteriyal bileşikler olarak görev yaptığı da belirtilmiştir [9-11]. Bu bileşik sınıflarından ilk keşfedilen taç eterlere dair gelişmelere baktığımızda, floresans sensör, faz transfer katalizörü, likit kristaller olarak kullanıldıklarını hatta son yıllarda taç eterlerin kanser araştırmalarında kullanıldığına dair yayınların olduğu bilinmektedir [12-16].

Ancak yapılan kapsamlı literatür taramasına rağmen tiyofen, furan ve pirol halkaları ile gerçekleștirilen makrosiklik halka sentezlerine pek rastlanmamıştır ve bu nedenle sentezlenen bileşiklerin de özelliklerinin incelenmesi ve farklı uygulamalarda kullanımı büyük önem taşımaktadır.

$\mathrm{Bu}$ çalışmada furan ve tiyofen halkası içeren iki yeni makrosiklik bileşik literatürde bulunan metodlara 
benzer olarak sentezlenip, yapıları ${ }^{1} \mathrm{H}-\mathrm{NMR},{ }^{13} \mathrm{C}$ ve HRMS ile aydınlatılmıştır ve antimikrobiyal ve antifungal aktiviteleri incelenmiştir.

\section{Materyal ve Metot}

\subsection{Cihazlar}

Sentezlenen moleküllerin yapılarını aydınlatmak amaciyla, ${ }^{1} \mathrm{H}-$ ve ${ }^{13} \mathrm{C}$-NMR spektrumları dötero kloroform $\left(d_{1}-\mathrm{CDCl}_{3}\right)$ içinde sırasıyla Varian $300 \mathrm{MHz}$ ve Varian 75,5 MHz'de alınmıștır. Kütle ölçümleri için, LC Q-TOF elektron sprey iyonizasyon (ESI) modu ve atmosfer basıncı kimyasal iyonizasyon (APCI) modu kullanılmıştır.

Biyolojik aktivitelerin belirlenmesinde absorbans ölçümleri için Thermoscientific Multiskan Go multiplate spektrofotometresi kullanılmıştır.

\subsection{Sentez}

Hedeflenen bileşiklerin sentezinde, öncelikle başlangıç maddeleri olan 2,5-dihidroksimetil furan ve 2,5-dihidroksimetil tiyofen kendilerine karşılık gelen diasitlerden $\mathrm{LiAlH}_{4}$ varlığında THF çözücüsü içinde indirgenerek elde edildi [17]. Elde edilen ürünlerin yapısı literatürle karşılaştırılarak belirlenmiştir. Sentezlenen dioller, çeşitli reaktiflerle farklı reaksiyon şartlarında muamele edildi. Yapılan reaksiyonlara göre en iyi verimle, en saf şekilde elde edilen ürünün yapısı aydınlatıldı.

1,11(2,5)-difurana-3,6,9,13,16,19-heksaoksasikloeikosafan (5) ve 1,11(2,5)-ditiyofena-3,6,9,13,16,19heksaoksasikloeikosafan (6) bileşiklerinin sentezleri için izlenen yol aşağıda Şekil 1'de gösterilmiştir.
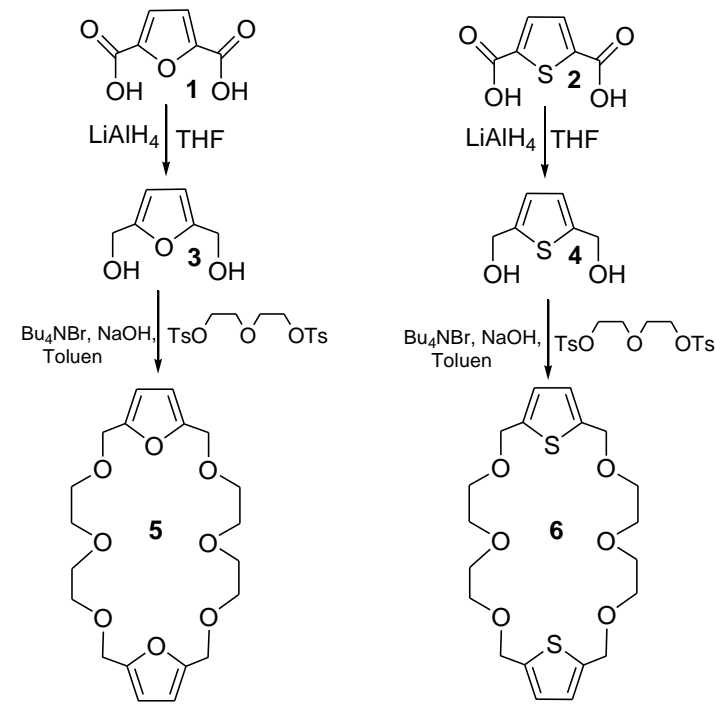

Şekil 1. Furan ve Tiyofen halkaları içeren makrosiklik eterlerin eldesi reaksiyonları

Reaksiyon için gerekli başlangıç maddeleri 2,5dihidroksimetil tiyofen ve 2,5-dihidroksimetil furan sentezlendikten sonra, ilgili makrosiklik bileşikleri sentezlemek için farklı bazlar ve farklı reaktifler denendi ve en iyi verimle ürün elde edilmeye çalışıldı. Çalışılan bazlar ve reaktifler Tablo 1'de verilmiştir.

\subsubsection{1,11(2,5)-difurana-3,6,9,13,16,19- heksaoksasikloeikosafan bileşiğinin eldesi (5)}

$0.2 \mathrm{~g}$ 2,5-dihidroksimetilfuran, $0.12 \mathrm{~g}$ tetrabütil amonyum bromür $10 \mathrm{~mL}$ toluende çözüldü ve 60 ${ }^{\circ} \mathrm{C}^{\prime}$ de isıtıldı. Ardından içine $7 \mathrm{~mL} \% 50$ 'lik $\mathrm{NaOH}$ eklendi ve $30 \mathrm{dk}$ isıtıldıktan sonra $10 \mathrm{~mL}$ toluende çözülmüş $0.99 \mathrm{~g}$ bis(2-tosiloksietil) eter eklendi ve 16 saat ısıtıldı. Organik faz ayrıldı ve $3 \mathrm{kez}$ su ile yıkama yapıldı. Organik faz $\mathrm{MgSO}_{4}$ üzerinden kurutuldu ve toluen uçuruldu [18]. Kalıntı $n$-heksan ile kaynatıldı ve $n$-heksan fazı ayrıldı. $n$-Heksanda çözünen kısım flash kromatografisi ile $n$-heksan kullanılarak saflaştırıldı. Verim: \% 50

\subsection{2. $1,11(2,5)$-ditiyofena-3,6,9,13,16,19- heksaoksasikloeikosafan bileşiğinin eldesi (6)}

$0.5 \mathrm{~g}$ 2,5-dihidroksimetiltiyofen, $0.3 \mathrm{~g}$ tetrabütil amonyum bromür $25 \mathrm{~mL}$ toluende çözüldü ve 60 ${ }^{\circ} \mathrm{C}$ 'de isitıldı. Ardından içine $15 \mathrm{~mL} \% 50$ 'lik $\mathrm{NaOH}$ eklendi ve $30 \mathrm{dk}$ isıtıldıktan sonra $20 \mathrm{~mL}$ toluende çözülmüş $1.45 \mathrm{~g}$ bis(2-tosiloksietil) eter eklendi ve 24 saat ısıtıldı. Organik faz ayrıldı ve $3 \mathrm{kez}$ su ile yıkama yapıldı. Organik faz $\mathrm{MgSO}_{4}$ üzerinden kurutuldu ve toluen uçuruldu [18]. Kalıntı $n$-heksan ile kaynatıldı ve uçurulan $n$-heksan fazı silika üzerinden çözücü olarak $n$-heksan ile flash kromatografisi yapıldı. Verim: \% 60

\subsection{Antibakteriyal ve antifungal aktiviteler}

Çalışmada Klinik Laboratuar Standartlar Enstitüsü (CLSI) tarafından önerilen Besiyeri Mikro-Seyreltme (Broth Microdilution) yöntemi kullanılarak minimum inhibisyon konsantrasyon (MIC) değerleri belirlenmiştir [19]. Bu amaçla Gram-Escherichia coli ATCC 25922, Gram + Staphylococcus aureus ATCC 25923, Gram - Listeria monocytogenes ATCC 19115, Gram - Salmonella thphimurium ATCC 14028, Bacillus cereus bakterileri ve Candida albicans ATCC 10231 mayası ile çalışılmıştır. Bakteriler 24 saat $37{ }^{\circ} \mathrm{C}^{\prime} \mathrm{de}$ Tryptic Soy besiyerinde inkübe edilmiştir ve McFarland Skalası da 0.5 'e ayarlanmıştır. Antibiyotik kontrolü olarak bakteri kültüründe Ampisilin ve Gentamisin, maya kültüründe ise Amphotericin B kullanılmıștır. Sterilite amacıyla antibiyotikler ve çözünen madde stok çözeltileri $0,45 \mu \mathrm{m}$ steril filtreden süzülmüşlerdir. Kontrol olarak da antibiyotik ve DMSO kullanılmıștır. Madde konsantrasyonları 16-256 ppm olacak şekilde ayarlanmıştır. Her bir kuyuya bakteri ve maya kültürlerinden ve sentezlenen 1,11(2,5)-difurana$3,6,9,13,16,19$ heksaoksasikloeikosafan ve $1,11(2,5)$ ditiyofena-3,6,9,13,16,19-heksaoksasikloeikosafan ilave edilmiştir. Bütün mikro plateler 24 saat $37^{\circ} \mathrm{C}^{\prime}$ de inkübe edilmiştir ve $600 \mathrm{~nm}$ 'de absorbans ölçülerek sonuçlar belirlenmiştir. 
Tablo 1. Makrosiklik eterleri sentezleme yöntemleri

\begin{tabular}{|c|c|c|c|c|c|}
\hline No & Reaksiyonda kullanılan & Reaksiyon & Süre & Sonuç & \\
\hline & reaktif & şartları & & 5 & 6 \\
\hline 1 & $\begin{array}{l}\mathrm{Cl} \\
(7)\end{array}$ & $\mathrm{CH}_{2} \mathrm{Cl}_{2}$, Piridin & 72 saat & $\begin{array}{l}\text { Başlangıç } \\
\text { maddesi geri } \\
\text { kazanıldı }\end{array}$ & $\begin{array}{l}\text { Başlangıç } \\
\text { maddesi geri } \\
\text { kazanıldı }\end{array}$ \\
\hline 2 & $\begin{array}{l}\mathrm{Cl} \\
(7)\end{array}$ & $\mathrm{K}_{2} \mathrm{CO}_{3}, \mathrm{CH}_{3} \mathrm{CN}$ & 72 saat & $\begin{array}{l}\text { Başlangıç } \\
\text { maddesi geri } \\
\text { kazanıldı }\end{array}$ & $\begin{array}{l}\text { Başlangıç } \\
\text { maddesi geri } \\
\text { kazanıldı }\end{array}$ \\
\hline 3 & $\begin{array}{l}\mathrm{Cl} \\
(7)\end{array}$ & $\mathrm{K} t \mathrm{BuO}, \mathrm{THF}$ & 72 saat & 〜 5 verim & 〜\% 5 verim \\
\hline 4 & $\begin{array}{l}\mathrm{Cl} \\
(7)\end{array}$ & $\begin{array}{l}\text { NaH, THF ve } \\
\text { NaH, DMF }\end{array}$ & 72 saat & $\begin{array}{l}\text { \% 10 verim } \\
\text { ve çok fazla } \\
\text { yan ürün }\end{array}$ & $\begin{array}{l}\text { \% } 10 \text { verim } \\
\text { ve çok fazla } \\
\text { yan ürün }\end{array}$ \\
\hline 5 & $\begin{array}{l}\text { Tso' } \\
(8)\end{array}$ & $\begin{array}{l}\mathrm{K}_{2} \mathrm{CO}_{3}, \quad \mathrm{KBF}_{4}, \\
\mathrm{CH}_{3} \mathrm{CN}\end{array}$ & 72 saat & $\begin{array}{l}\text { Başlangıç } \\
\text { maddesi geri } \\
\text { kazanıldı }\end{array}$ & $\begin{array}{l}\text { Başlangıç } \\
\text { maddesi geri } \\
\text { kazanıldı }\end{array}$ \\
\hline 6 & $\begin{array}{c}\mathrm{TsO} \\
(8)\end{array}$ & $\begin{array}{l}\mathrm{Bu}_{4} \mathrm{NBr}, \mathrm{NaOH}, \\
\text { Toluen }\end{array}$ & 24 saat & $\% 50$ verim & $\% 60$ verim \\
\hline
\end{tabular}

\section{Bulgular}

Yukarıdaki Tablo 1'i incelediğimizde, 1 no'lu reaksiyonda baz olarak piridin, çözücü olarak $\mathrm{CH}_{2} \mathrm{Cl}_{2}$, 2 no'lu reaksiyonda baz olarak potasyum karbonat, çözücü olarak $\mathrm{CH}_{3} \mathrm{CN}, 3$ no'lu reaksiyonda baz olarak potasyum ter-bütoksit, çözücü olarak THF, 4 no'lu reaksiyonda, baz olarak sodyum hidrür, çözücü olarak THF yada DMF, 5 no'lu reaksiyonda baz olarak $\mathrm{K}_{2} \mathrm{CO}_{3}$, katalizör olarak $\mathrm{KBF}_{4}$, çözücü olarak $\mathrm{CH}_{3} \mathrm{CN}, \mathbf{6}$ no'lu reaksiyonda baz olarak $\mathrm{NaOH}$, katalizör olarak $\mathrm{Bu}_{4} \mathrm{NBr}$, ve çözücü olarak toluen kullanıldı. 1-4 arası reaksiyonlarda reaktif olarak bis-2-kloroetil eter kullanılırken, 5 ve $\mathbf{6}$ no'lu reaksiyonda ise reaktif olarak bis(2-tosiloksietil) eter kullanıldı. Bu reaktif de literatürde var olan metoda göre, 2-oksietandiol'den başlanarak p-toluensülfonil klorür, $\mathrm{KOH}$ ve $\mathrm{CH}_{2} \mathrm{Cl}_{2}$ varlığında sentezlendi [20]. Literatürle karşılaștırılarak yapı desteklenmiştir.

\section{(5)}

1H-NMR (300 MHz, $\mathbf{C D C l}_{3}$ ): 3.52-3.80(m, 4H, $\left.\mathrm{CH}_{2}\right)$, $4.56\left(\mathrm{dd}, \mathrm{j}=27.9,6.9 \mathrm{~Hz}, 2 \mathrm{H}, \mathrm{CH}_{2}\right), 6.26(\mathrm{~s}, 1 \mathrm{H}, \mathrm{CH})$. ${ }^{13}$ C-NMR (75 MHz, $\mathbf{C D C l}_{3}$ ) $\delta$ : $66.98,70.50,71.79$, 128.24, 145.96.

LC-Q/TOF (Deneysel) : $397.1862[\mathrm{M}+1]^{+}$

LC-Q/TOF (Teorik + H) : $397.1862[\mathrm{M}+1]^{+}$
(6)

${ }^{1} \mathrm{H}-\mathrm{NMR}\left(\mathbf{3 0 0} \mathbf{M H z}, \mathbf{C D C l}_{3}\right)$ : 3.54-3.72 (m, 4H, $\left.\mathrm{CH}_{2}\right)$, $4.66\left(\mathrm{~s}, 2 \mathrm{H}, \mathrm{CH}_{2}\right), 6.84(\mathrm{~s}, 1 \mathrm{H}, \mathrm{CH})$.

${ }^{13}$ C NMR (75 MHz, $\mathbf{C D C l}_{3}$ ): 68.12, 69.04, 70.92, $126.20,141.49$.

LC-Q/TOF (Deneysel): 429.092[M+1] ${ }^{+}$

LC-Q/TOF (Teorik +H) $429.1405[\mathrm{M}+1]^{+}$

Makrosiklik bileşiklerin sentezinde kullanılan başlangıç maddeleri, 2,5-dihidroksimetil furan ve 2,5dihidroksimetil tiyofen, ticari olarak satılan 2,5furandikarboksilik asit ve 2,5-tiyofendikarboksilik asitten $\mathrm{LiAlH}_{4}$ varlığında THF çözücüsü içinde indirgenme reaksiyonu ile sentezlenmiştir. Elde edilen alkollerin yapıları ${ }^{1} \mathrm{H}-\mathrm{NMR}$ alınıp literatürle karşılaştırıldıktan sonra aydınlatılmış ve Tablo 1'deki reaksiyonlar ayrı ayrı denenmiş ve en iyi reaksiyon şartları tespit edilmiştir. Tablo 1'deki 1 no'lu reaksiyon çözücü olarak $\mathrm{CH}_{2} \mathrm{Cl}_{2}$ içinde piridin varlığında gerçekleștirilerek istenilen ürün elde edilememiștir. 2 no'lu reaksiyonda ise baz olarak potasyum karbonat kullanılmış ve çözücü olarak asetonitril kullanılarak sentez gerçekleștirilmiștir. $\mathrm{Bu}$ çözücü ile de istenilen ürün elde edilememiştir. Aynı maddenin sentezi potasyum ter-bütoksit, THF ile tekrarlandığında sadece \% 5 gibi oldukça düşük bir verimle 5 ve 6 no'lu bileşikler elde edilebilmiştir. 4 no'lu deney ise baz olarak $\mathrm{NaH}$ kullanılarak iki farklı çözücüde (THF ve DMF) denenmiştir. Fakat elde edilen ürün miktarı çok az olduğu için, kullanılan 
reaktif değiştirilip, bis(2-tosiloksietil) eter literatürdeki metoda göre sentezlenip, diğer deneylerde kullanılmıştır. Bis(2-tosiloksietil) eter ile gerçekleştirilen deneylerde $\mathrm{K}_{2} \mathrm{CO}_{3}, \mathrm{KBF}_{4}, \mathrm{CH}_{3} \mathrm{CN}$ veya $\mathrm{Bu}_{4} \mathrm{NBr}, \mathrm{NaOH}$, toluen sistemleri kullanılmıștır. Bu sistemlerden en iyi çalışan $\mathrm{Bu}_{4} \mathrm{NBr}, \mathrm{NaOH}$, toluen sistemi olmuştur. İstenilen ürünler iyi verimlerle elde edilmiştir. Elde edilen ürünlerin yapıları aydınlatıldıktan sonra, antifungal ve antibakteriyel özellikleri araştırılmıştır.

5 ve 6 no'lu bileşiklerin antifungal ve antibakteriyel aktiviteleri 16, 32, 64, 128 ve $256 \mu \mathrm{M}^{\prime} \mathrm{l}$ lk konsantrasyonlarda beş bakteri ve bir maya üzerinde araştırılmıștır. Bakterilerde ampisilin ve gentamisin, mayada ise amphotericin-b antibiyotikleri 8 ve 16 $\mu \mathrm{M}^{\prime} \mathrm{l}$ lk konsantrasyonlarda kontrol olarak kullanılmıştır. 96 kuyucuklu plakalara ekilen bakteri ve maya üzerine 5 ve $\mathbf{6}$ no'lu bileşikler ve farklı antibiyotik konsantrasyonları ayrı ayrı ilave edilmiş ve $37^{\circ} \mathrm{C}$ de 24 saat inkübasyona bırakılmıştır. İnkübasyon sonunda elisa plaka okuyucuda $600 \mathrm{~nm}$ dalga boyunda okumaları yapılarak absorbans değerleri ölçülmüştür. Aktivite testlerinin uygulandığı bakteriler Escherichia coli ATCC 25922, Salmonella thphimurium ATCC 14028, Staphylococcus aureus ATCC 25923, Bacillus cereus ATCC 11778, ve Listeria monocytogenes ATCC 19115 iken, antifungal aktivite Candida albicans ATCC 10231 mayası üzerinde belirlenmiştir. Alınan sonuçların grafiği çizilmiştir ve bu sonuçlar grafiklerden izlenebilir.

Tablo 2. 5 No'lu bileşiğin antimikrobiyal aktivite sonuçları

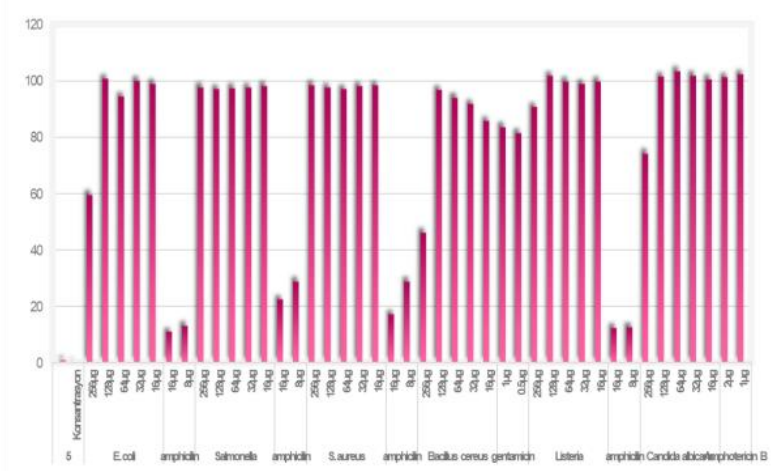

Tablo 3. 6 No'lu bileşiğin antimikrobiyal aktivite sonuçları

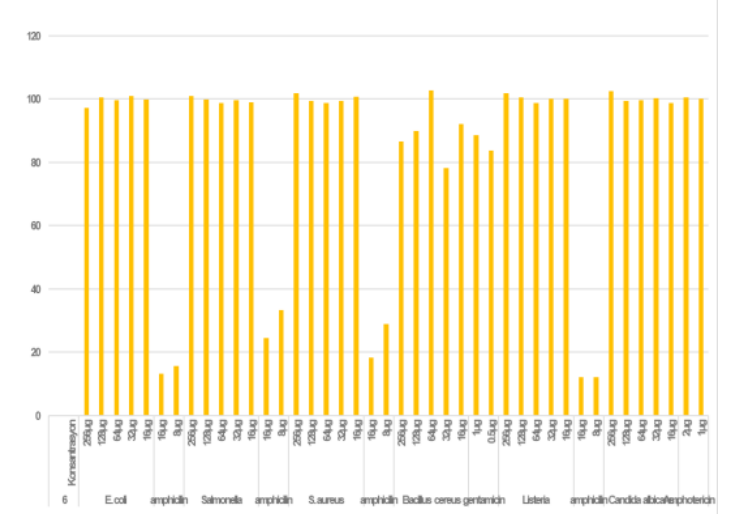

\section{Tartışma ve Sonuç}

Bu çalışmada, furan ve tiyofen halkası içeren iki yeni makrosiklik bileşik farklı reaksiyon şartları denenerek elde edilmeye çalışılmış ve en uygun metod belirlenerek iyi verimle hedeflenen bileşikler sentezlenmiştir. Bu bileşiklerin ayrıca antimikrobiyal aktiviteleri incelenmiş ve yüzde canlılığa karşılık konsantrasyon grafiği çizilmiştir. Bu sonuçlara göre, (5) no'lu bileşiğin Candida albicans ATCC 10231'e karşı çok az etki gösterdiği, Escherichia coli ATCC 25922 ve Bacillus cereus ATCC 11778'e karşı llımlı etki gösterdiği, (6) no'lu maddenin ise seçilen mikroorganizmalara karşı etkin olmadığı gözlenmiştir.

\section{Teşekkür}

Bu çalıșma Trakya Üniversitesi Rektörlüğü Araștırma Fonu tarafindan 2014/042 numaralı proje olarak desteklenmiştir. Katkılarından dolayı Araştırma Fonuna, Prof. Dr. Ömer Zaim'e teşekkürlerimi sunarım.

\section{Kaynakça}

[1] Fenton, R. R., Gauci, R., Junk, P.C., Lindoy, L. F., Luckay, R. C., Meehan, G. V., Price, J. R., Turner, P., ve Wei, G. 2002. Macrocyclic ligand design. Structure- function relationships involving the interaction of pyridinyl-containing, mixed oxygen-nitrogen donor macrocycles with cobalt(II), nickel(II), copper(II), zinc(II), cadmium(II), silver(I) and lead(II). Journal of Chemical Society, 10 (2002), 2185-2193.

[2] Aghatabay, N. M., Mahmiani, Y., Cevik, H., Gucin, F., ve Dulger, B. 2008. Synthesis, FT-Raman, FTIR, NMR spectroscopic characterization and antimicrobial activity of new mixed aza-oxothia macrocyclic compounds. Structural Chemistry, $19 \quad$ (2008), 833-842.

[3] Hughes, R. A., Thompson, S. P., Alcaraz, L.,ve Moody, C. J. 2005. Total Synthesis of the Thiopeptide Antibiotic Amythiamicin D. Journal of American Chemical Society 127 (2005), 15644-15651.

[4] Napolitano, A., Rodriquez, M., Bruno, I., Marzocco, S., Autore, G., Riccioa, R., Gomez-Paloma, L.:2003. Synthesis, structural aspects and cytotoxicity of the natural cyclopeptides yunnanins $\mathrm{A}, \mathrm{C}$ and phakellistatins 1 . Tetrahedron, 59 (2003), 10203-10211.

[5] Rajakumar, P., Rasheed, A. M. A., Rabia, A. I., ve Chamundeeswari, D. 2006. Synthesis and study of anti-inflammatory activity of some novel cyclophane amides. Bioorganic and Medicinal Chemistry Letters, 16 (2006), 6019-6023.

[6] Bokesch, H.R., Pannell, L.K., Cochran, P.K., Sowder, R.C., McKee, T.C., Boyd, M.R. 2001. A novel anti- 
HIV macrocyclic peptide from Palicourea condensataI. Journal of Natural Products, 64 (2001), 249-250.

[7] Armstrong, L. G ve Lindoy. L. F. 1975. Nitrogenoxygen donor macrocyclic ligands. I. Nickel(II) complexes of a new series of cyclic ligands derived from salicylaldehydes. Inorganic Chemistry, 14 (1975), 1322-1326.

[8] Reed, J. J., Bradshaw, J. S., Husathy, P., Izatt, R. M. ve Dalley, N. K. 1998. Synthesis and Complexation Properties of Pyrimidine-Derived Crown Ether Ligands. Journal of Heterocyclic Chemistry, 35 (1998), 1-8.

[9] Herrera, A. M., Kalayda, G. V., Disch, J. S., Wikstrom, J. P., Karendovych, I. V.,Staples, R. J., Campana, C. F., $\quad$ Nazarenko, A.Y., Haas, T. E. ve Rybak-Akimovz 2003. Reactions at the azomethine $\mathrm{CN}$ bonds in the nickel(II) and copper(II) complexes of pyridine- containing Schiff-base macrocyclic ligands. Dalton Trans, (2003), 4482-4492.

[10] Zaim, Ö., Aghatabay N. M, Gürbüz M.U., Baydar C.., ve Dülger B. 2014. Synthesis, structural aspects, antimicrobial activity and ion transport investigation of five new [1+1] condensed cycloheterophane peptides. Journal of Inclusion Phenomena and Macrocyclic Chemistry, 78, (2014), 151-159.

[11] Aghatabay N. M., Parali Ö., Zaim Ö., Baydar Ç., Dülger B. 2014. Synthesis, structural aspects, antimicrobial activity and ion transportation investigation of four new [2 + 2] condensed 24 membered cycloheterphane peptides. Journal of Inclusion Phenomena and Macrocyclic Chemistry, 79, (2014), 415-424.

[12] Gourdet, B., Singh, K., Stuart, A. M., Vidal, J. A. 2010. Di(1H,1H,2H,2H-perfluorooctyl)-dibenzo 18-crown-6: A "light fluorous" recyclable phase transfer catalyst. Journal of Fluorine Chemistry, 131, (2010), 1133-1143.
[13] Li, Y., Yang, H., Zhao, Q., Song, W., Han, J., Bu, X. 2012. Ratiometric and Selective Fluorescent Sensor for Zn2+ as an "Off-On-Off" Switch and Logic Gate. Inorganic Chemistry, 51, (2012), 9642-9648.

[14] Zhang, C., Pu, J., Wu, H., Cheng, S., Zhang, R., Zhagn, A., Zhang, M. 2011. The synthesis and mesophases studies of a novel discotic compound containing two triphenylene cores linked by crown ether. Molecular Crystals and Liquid Crystals, 542, (2011), 99-105.

[15] Ihara, T., Sueda, S., Inenaga, A., Fukuda, R. ve Takagi, M. 1997. Synthetic DNA Ligands Conjugated with Metal Binding Moiety. Regulation of the Interaction with DNA by Metal Ions and the Ligand Effect on Metal Assisted DNA Cleaving. Supramolecular Chemistry, 8 (1997), 93-111.

[16] McPhee, M. M. ve Kerwin S. M. 2001. Synthesis, DNA cleavage, and cytotoxicity of a series of bis(propargylic) sulfone crown ethers. Bioorganic and Medicinal Chemistry, 9, (2001), 2809-2818.

[17] Boyer, A. and Lautens, M. 2011. Rhodium catalyzed domino enantioselective synthesis of bicyclo[2.2.2]lactones. Angewandte Chemie 5, (2011), 7346-7349.

[18] T. Bogaschenko, S. Basok, C. Kulygina, A. Lyapunov, N. Lukyanenko, 2002. A Practical Synthesis of Benzocrown Ethers under PhaseTransfer Catalysis Conditions. Synthesis, 15 (2002), 2266-2270.

[19] CLSI 2006 M7- A7, Methods for Dilution Antimicrobial Susceptibility Tests for Bacteria That Grow Aerobically.

[20] Kimberly M. Bongera, Richard J.B.H.N. van den Berga, Laura H. Heitmanb, Ad P. IJzermanb, Julia Oosteromc, Cornelis M. Timmersd, Herman S. Overkleefta, Gijsbert A. van der Marela, 2007. Synthesis and evaluation of homo-bivalent GnRHR ligands. Bioorganic and Medicinal Chemistry, 15, (2007), 4841-4856. 